\title{
Airway Obstruction and Bronchodilator Responsiveness in Adults With Acute Cough
}

Saskia van Vugt, MD, MSc

Lidewij Broekbuizen, MD, PbD

Nicolaas Zuithoff, MSc, PbD

Christopher Butler, $M D, P b D$

Kerenza Hood, PbD

Samuel Coenen, MD, PbD

Herman Goossens, MD, PbD

Paul Little, MD, $P b D$

Jordi Almirall, $M D, P b D$

Francesco Blasi, MD, $P b D$

Slawomir Cblabicz, MD, PbD

Mel Davies, RN, PbD

Maciek Godycki-Cwirko, MD, PbD

Helena Hupkova, MD, PbD

Janko Kersnik, MD, $P b D$

Michael Moore, MD, $P b D$

Tom Schaberg, MD, PbD

An De Sutter, MD, PbD

Antoni Torres, MD, PbD

Theo Verbeij, MD, $P b D$

On behalf of the GRACE Project Group

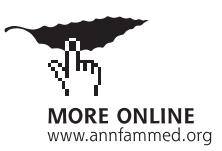

Conflicts of interest: authors report none.

\section{CORRESPONDING AUTHOR}

Lidewij Broekhuizen, MD, PhD

Julius Center for Health Sciences and

Primary Care

Stratenum 6.131 - P.O.Box 85500,

NL- 3508 GA

Utrecht, the Netherlands

b.d.l.broekhuizen@umcutrecht.nl

\begin{abstract}
PURPOSE We sought to determine the prevalence of airway obstruction and bronchodilator responsiveness in adults consulting for acute cough in primary care.

METHODS Family physicians recruited 3,105 adult patients with acute cough (28 days or shorter) attending primary care practices in 12 European countries. After exclusion of patients with preexisting physician-diagnosed asthma or chronic obstructive pulmonary disease (COPD), we undertook complete case analysis of spirometry results ( $n=1,947) 28$ to 35 days after inclusion. Bronchodilator responsiveness was diagnosed if there were recurrent complaints of wheezing, cough, or dyspnea and an increase of the forced expiratory volume in 1 second $\left(\mathrm{FEV}_{1}\right)$ of $12 \%$ or more after bronchodilation. Airway obstruction was diagnosed according to 2 thresholds for the (postbronchodilator) ratio of $\mathrm{FEV}_{1}$ to forced vital capacity (FEV 1 :FVC): less than 0.7 and less than the lower limit of normal.
\end{abstract}

RESULTS There were 240 participants who showed bronchodilator responsiveness (12\%), 193 (10\%) had a FEV $/$ FVC ratio of less than 0.7, and 126 (6\%) had a ratio of less than the lower limit of normal. Spearman's correlation between the 2 definitions of obstruction was $0.71(P<.001)$, with discordance most pronounced among those younger than 30 years and in older participants.

CONCLUSIONS Both bronchodilator responsiveness and persistent airway obstruction are common in adults without established asthma or COPD who consult for acute cough in primary care, which suggests a high risk of undiagnosed asthma and COPD. Different accepted methods to define airway obstruction detected different numbers of patients, especially at the extremes of age. As both conditions benefit from appropriate and timely interventions, clinicians should be aware and responsive to potential underdiagnosis.

Ann Fam Med 2012;10:523-529. doi:10.1370/afm.1416.

\section{INTRODUCTION}

U ndetected chronic obstructive lung disorders in primary care, such as asthma and chronic obstructive pulmonary disease (COPD), are common in high-risk patients (eg, smokers) who complain of acute cough. ${ }^{1,2}$ Cough is among the most common conditions for which people seek health care, ${ }^{3}$ and family physicians could help their patients by considering underlying asthma or COPD when their patients consult them for acute cough. Timely treatment improves quality of life and reduces future exacerbations of these underlying conditions., ${ }^{4,5}$

Our searches identified only 2 relevant studies describing the proportion of underlying obstructive lung disorders in patients consulting their family physician for cough. Thiadens and colleagues ${ }^{6}$ included 192 patients (mean age of 44 years) consulting their family physician for cough persisting for at least 14 days; 74 were given a diagnosis of asthma (39\%), and 14 were given a diagnosis of COPD (7\%). Broekhuizen and colleagues ${ }^{7}$ included 353 patients (mean age of 63 years) with cough lasting more than 14 days, 23 of whom were given a diagnosis of asthma (7\%) and 102 were given a diagnosis of COPD (29\%). Both studies were relatively small and the mean duration of 
cough in the latter study was long (93 days). More frequent visits and persistent cough are known to be associated with diagnosis of COPD ${ }^{8}$ whereas the relation with underlying obstructive airways disease and acute cough ( $\leq 28$ days) has not previously been quantified.

We therefore set out to determine the prevalence of abnormal lung function results that could identify patients at high risk for a diagnosis of COPD or asthma in a large multicenter study of adult patients consulting their primary care physicians with acute cough.

\section{METHODS}

Ours was a cross-sectional prevalence study. Data were collected in 16 primary care research networks in 12 European countries participating in the Genomics to Combat Resistance Against Antibiotics in Communityacquired LRTI in Europe (GRACE) (http://www.grace1rti.org) Network of Excellence. Participating family physicians recruited consecutive patients who were aged 18 years or older, with acute cough as the main symptom, and consulting for the first time for this disease episode. Although acute cough is usually defined as fewer than 21 days, some studies have shown that cough can last more than 3 weeks. ${ }^{9}$ We therefore decided to adopt the broader inclusion criterion of 28 days or less for acute cough. Nonwhite patients were excluded because of ethnic differences in lung function reference values. ${ }^{10}$ Other exclusion criteria for this analysis were diagnosis of asthma or COPD in the clinical record at the time of the index consultation and serious causes of compromised immunity. All patients provided written informed consent, and the study was approved by the medical ethics committees of all participating centers.

\section{Measurements}

Family physicians recorded the participants' history (eg, current complaints, comorbidity, medications) and findings from the physical examination on a standardized case report form. Spirometry was performed according to a strict protocol between day 28 and 35 after inclusion with the aim of obtaining results during a stable phase. ${ }^{4,11}$ Staff in the participating primary care centers underwent standardized training in spirometry. Measurements included the forced vital capacity (FVC) and the forced expiratory volume in 1 second $\left(\mathrm{FEV}_{1}\right)$ before and at least 15 minutes after bronchodilation with $400 \mathrm{mg}$ of salbutamol. The best of a minimum of 3 acceptable retained flow volume curves was used to determine the postbronchodilator $\mathrm{FEV}_{1}$ : FVC ratio. ${ }^{4}$

\section{Diagnostic Outcome}

Bronchodilator responsiveness was diagnosed if recurrent (more than 1 other episode in the past year) wheezing, cough, or chest tightness were present (patient reported) in combination with an increase in $\mathrm{FEV}_{1}$ of at least $12 \%$ or more than $200 \mathrm{~mL}$ after bronchodilation. Persistent airway obstruction was diagnosed on the basis of the postbronchodilator $\mathrm{FEV}_{1}:$ FVC ratio. According to the Global Initiative for Chronic Obstructive Lung Disease (GOLD), a ratio of less than 0.7 confirms COPD. ${ }^{4}$ Because the $\mathrm{FEV}_{1}$ :FVC ratio physiologically decreases with age, however, there is controversy about using a fixed threshold to define obstruction ${ }^{4,12}$; others base a definition of obstruction on the lower limit of normal (LLN) of the $\mathrm{FEV}_{1}$ :FVC ratio according to sex and age. ${ }^{13}$ The presence of airway obstruction in our study was defined by both methods: (1) a fixed $\mathrm{FEV}_{1}: \mathrm{FVC}$ ratio of less than 0.7 according to GOLD (obstruction GOLD), and (2) $\mathrm{FEV}_{1}$ :FVC ratio of less than the LLN according to the European Respiratory Society guidelines (obstruction LLN). ${ }^{14}$ Correlation between the 2 definitions was calculated with Spearman's rank correlation coefficient. ${ }^{15}$

\section{Data Analysis}

Only participants with complete spirometry results were included in the present analysis. For the included participants, missing results (apart form spirometry) were imputed using multiple regression techniques. Data were analyzed using SPSS 17.0 for Windows (SPSS Inc) and R 2.8.1 (R Project for Statistical Computing). ${ }^{16}$ The prevalence of asthma, COPD GOLD, and COPD LLN was calculated for the entire study population and for subgroups of age, sex, and smoking history (current, past, never). These groups were compared using $\chi^{2}$ tests.

\section{RESULTS}

\section{Patient Characteristics}

Family physicians recruited 3,105 participants with acute cough. Participants with preexisting physiciandiagnosed (according to the physicians' medical file) asthma ( $n=329)$, physician-diagnosed COPD ( $n=183)$, those who were of nonwhite ethnicity $(n=87)$, and those who had incomplete spirometry results $(n=585)$ were excluded, resulting in 1,947 participants for the analysis (Figure 1). ${ }^{10}$ Less than $0.1 \%$ of history items, $1 \%$ of physical examination items, and $12 \%$ of diary data were missing (Table 1). In some countries, spirometry measurements were available for only a minority of participants (eg, Italy and Slovakia, Supplemental Appendixes 1 and 2, available at http://annfammed.org/content/10/6/523/suppl/DC1). There were no important differences between study participants with and without spirometry results, apart from mean age (46 years for those without spirometry, 
data not shown). The mean age of the study population was 50 years ( $\mathrm{SD}=16$ years), $40 \%(\mathrm{n}=770)$ were male, mean height was $168 \pm 9 \mathrm{~cm}$, and mean weight was $76 \pm 16 \mathrm{~kg}$. Mean duration of cough before consultation (9 days) and average day of recovery (12 days) were similar in participants with and without undetected asthma or COPD.

\section{Prevalence of Obstruction and Reversibility}

Of the 1,947 participants, 240 met our diagnostic criteria for bronchodilator responsiveness (12\%), of

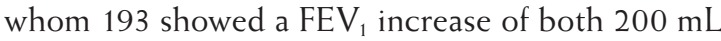
and $12 \% ; 193$ (10\%) had airway obstruction GOLD and $126(6 \%)$ had airway obstruction LLN (Spearman's $\rho=0.71, P<.001)$. Of the participants with obstruction GOLD and LLN, 92 and 67, respectively, reported recurrent respiratory symptoms (more than 2 cough episodes or had awakened with more than once with chest tightness last year).

In total, 202 (10\%) participants met obstruction criteria according to at least 1 of the 2 definitions, and 41 participants showed both bronchodilator responsiveness and obstruction (2\%) (Table 1). Of the 193 participants with obstruction GOLD, 86 cases (45\%) had an $\mathrm{FEV}_{1}$ above the $80 \%$ predicted according to age, sex, and height; 84 (44\%) had an $\mathrm{FEV}_{1}$ between the

\section{Figure 1. Flowchart of the study and participants.}

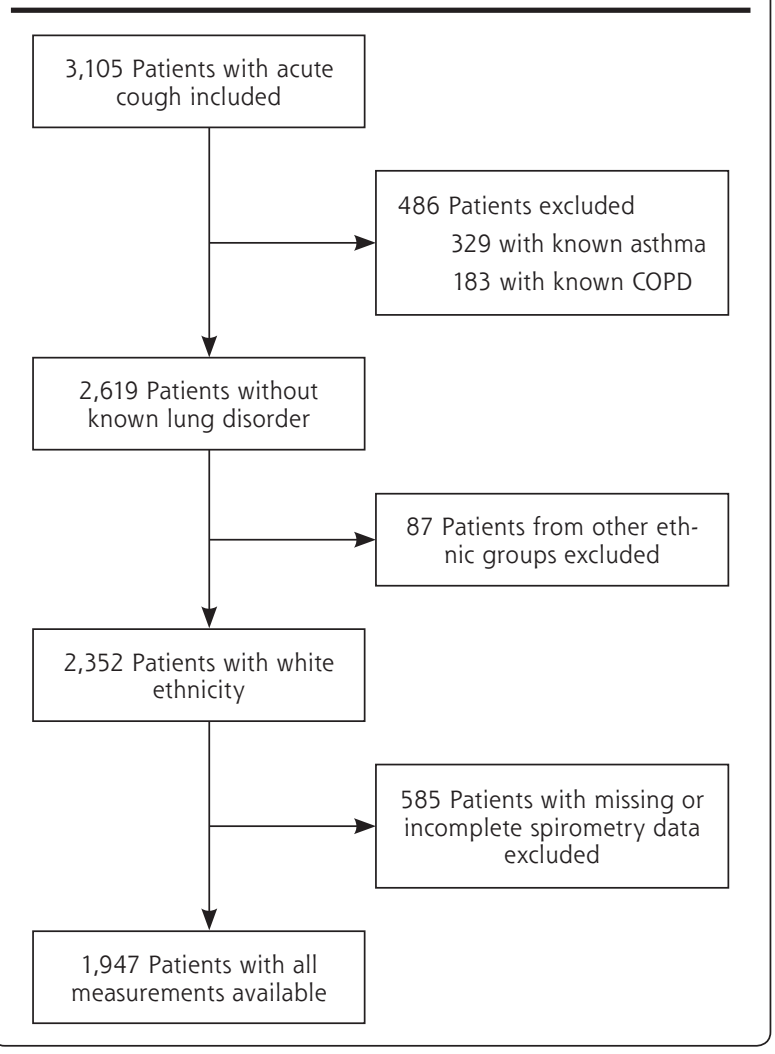

$50 \%$ and $80 \%$ predicted $_{i} 17(8 \%)$ had an $\mathrm{FEV}_{1}$ between the $30 \%$ and $50 \%$ predicted, and 6 (3\%) had an FEV of less than the $30 \%$ predicted.

The prevalence of bronchodilator responsiveness and airway obstruction (GOLD or LLN) varied largely per country and was related to the proportion of known asthma and COPD (Supplemental Appendix 2, available at http://annfammed.org/content/10/6/523/ suppl/DC1).

The prevalence of bronchodilator responsiveness was $15 \%$ in participants younger than 50 years and $11 \%$ in participants aged 50 years and older $(P=.004)$, $14 \%$ in male and $12 \%$ in female participants $(P=.18)$, $11 \%$ in never or past smokers, and $16 \%$ in current smokers $(P=.02)$. In participants with duration of cough shorter than 14 days at the first consultation, the prevalence of reversibility was $12 \%$ and $14 \%$ if duration was 14 days or longer $(P=.20$, Table 2$)$.

The prevalence of obstruction (GOLD or LLN) was $6 \%$ in participants younger than 50 years and $14 \%$ in participants aged 50 years and older $(P<.001), 11 \%$ in male and $10 \%$ in female participants $(P=.75), 9 \%$ in never smokers and $10 \%$ in past and $13 \%$ in current smokers $(P=.10)$. In participants with cough for fewer than 14 days at the first consultation, obstruction was found $10 \%$; in those with complaints longer than 14 days, it was $11 \%(P=.82$, Table 2$)$.

More participants showed obstruction GOLD than LLN, apart from in the under-30-year age-group, with the discordance highest in participants aged older than 50 years (14\% vs $7 \%$ for airway obstruction GOLD and LLN, respectively (Figure 2).

\section{DISCUSSION}

\section{Main Findings}

In adult patients without preexisting physician diagnosed asthma or COPD who consulted for acute cough in primary care and who underwent pre- and postbronchodilator spirometry 4 weeks later, $13 \%$ showed bronchodilator responsiveness, together with a history of recurrent airway symptoms. People with repeated episodes of acute cough and reversible airway obstruction may have undiagnosed asthma. Obstructive spirometry according to the GOLD definition was present in $10 \%$ and according to the LLN definition in $6 \%$ of the patients. The GOLD definition classified more participants with an obstructive condition than did the LLN definition, especially among older participants. Although these findings are necessary but not sufficient to diagnose COPD and asthma, patients with these findings are at higher risk of having (yet undetected) chronic obstructive lung disease and might benefit from ongoing treatment. 
Table 1. Characteristics of Adults Consulting for Acute Cough in Primary Care $(\mathrm{N}=1,947)$ by Presence of Bronchodilator Responsiveness

\begin{tabular}{|c|c|c|c|c|}
\hline \multirow[b]{2}{*}{ Characteristic } & \multirow{2}{*}{$\begin{array}{l}\text { Acute } \\
\text { Cough }\end{array}$} & \multirow[b]{2}{*}{ Responsiveness } & \multicolumn{2}{|c|}{ Airway Obstruction } \\
\hline & & & GOLD $^{a}$ & LLN $^{b}$ \\
\hline History (day 1), No. (\%) & $1,947(100)$ & $240(12)$ & $193(10)$ & $126(7 \%)$ \\
\hline Age, mean (SD), y & $50(16)$ & $47(17)$ & $58(16)$ & $50(17)$ \\
\hline Male, No. (\%) & $770(40)$ & $103(43)$ & $82(43)$ & $43(34)$ \\
\hline Current smoking, No. (\%) & $496(26)$ & $78(33)$ & $61(32)$ & $48(38)$ \\
\hline Pack-years of smoking, mean (SD), y & $8(14)$ & $9(17)$ & $13(20)$ & $14(21)$ \\
\hline History of cardiovascular disease, No. (\%) & $171(9)$ & $17(7)$ & $22(11)$ & $8(6)$ \\
\hline Use of inhaled lung medication, No. (\%) & $50(3)$ & $14(6)$ & $6(3)$ & $3(2)$ \\
\hline Asthma in parents or siblings, No. (\%) & $423(22)$ & $68(28)$ & $37(21)$ & $25(22)$ \\
\hline Atopy or allergic disease, No. (\%) ${ }^{d}$ & $732(38)$ & $116(48)$ & $71(40)$ & $52(46)$ \\
\hline Cough before consultation, mean (SD), d & $9(7)$ & $9(7)$ & $9(7)$ & $8(7)$ \\
\hline Cough episodes last year, mean (SD), No. & $2(2)$ & $3(2)$ & $2(2)$ & $2(2)$ \\
\hline \multicolumn{5}{|l|}{ Spirometry (day 28) } \\
\hline $\mathrm{FEV}_{1}$, mean $(\mathrm{SD}), \mathrm{L}$ & $3.0(0.9)$ & $3.2(1.1)$ & $2.1(0.7)$ & $2.0(0.8)$ \\
\hline FVC, mean (SD), L & $3.7(1.1)$ & $4.0(1.3)$ & $3.5(1.1)$ & $3.6(1.1)$ \\
\hline $\mathrm{FEV}_{1}: \mathrm{FVC}$ ratio, mean (SD) & $0.81(0.11)$ & $0.79(0.12)$ & $0.60(0.11)$ & $0.57(0.12)$ \\
\hline
\end{tabular}

ERS = European Respiratory Society; FEV $1=$ forced expiratory volume in 1 second; FVC = forced vital capacity; GOLD = Global Initiative for Chronic Obstructive Lung Disease; $L L N=$ lower limit of normal.

a According to the GOLD definition: $\mathrm{FEV}_{1}: \mathrm{FVC}$ less than 0.70 .

${ }^{b}$ According to ERS: LLN of FEV 1 :FVC ratio for males: $-0.18 \times$ age $+87.21-(1.64 \times 7.17)$, for females: $-0.19 \times$ age $+89.10-(1.64 \times 6.51) .{ }^{14}$

' These 41 participants are also included in the categories bronchodilator responsiveness and airway obstruction.

${ }^{d}$ Atopic symptoms or allergic disease $=$ hay fever, eczema, urticaria, or history of allergic reaction.

\section{Strengths and Limitations}

We studied a clinically relevant population, namely, those consulting their family physician for respiratory complaints (acute cough), whereas most previous studies included only asymptomatic volunteers (open-population studies). ${ }^{17-19}$ Moreover, we studied the prevalence of lung function abnormalities in 12 European countries, whereas most other studies were from a single country. Reviews mention considerable variation in reported prevalence of obstructive lung disease, attributed to differences in risk exposure, population characteristics, methods, and definitions used to measure disease. ${ }^{18,20}$ In our pan-European study, standardized measurements were used, and population differences were taken into account in analyses, increasing generalizability of the results. Finally, we measured spirometry results 4 weeks after an index consultation, when most acute episodes of cough had resolved.

A limitation of our study is that a formal clinical diagnosis of asthma and COPD could not be established within our research design. We were merely able to identify those with high risk of these disorders. Persistent airway obstruction is a hallmark of COPD (but can also develop in asthma, especially in smokers), and bronchodilator responsiveness suggests asthma and is common in COPD. There is no single reference standard to diagnose asthma and COPD; these diag- noses should be based on clinical history and physical examination combined with spirometry results. Repeat spirometry and additional tests, such as body plethysmography for COPD and histamine- or methacholineprovocation tests for asthma, can increase diagnostic certainty. We therefore considered that the diagnostic categories we used (bronchodilator responsiveness and airway obstruction) were most appropriate for reporting our results. Diagnostic certainty in our identified study participants could also have been be increased by specific questionnaires for asthma and COPD; however, the diagnostic value of such questionnaires is uncertain. Our findings reinforce the need for more objective criteria to define asthma or COPD

The differences in prevalence of airway obstruction and bronchodilator responsiveness that we found between countries might represent real differences, possibly caused by variation in air pollution or demographic characteristics. Moreover, the differences could also partly be explained by varying definitions and guidelines between countries, because an active detection policy for asthma and COPD reduces the number of undetected cases (Supplemental Appendix 2). A further limitation of our study is that differential patient selection (selection bias) between countries cannot be excluded, as we were not able to gather data on the eligible participants who were not included in the study. Another problem is the high number of 


\begin{tabular}{ccc}
$\begin{array}{c}\text { Responsiveness } \\
\text { and Obstruction } \\
\text { (GOLD or LLN) }\end{array}$ & $\begin{array}{c}\text { No Responsiveness } \\
\text { or Obstruction }\end{array}$ & Missing \\
\hline $41(2 \%)^{c}$ & $1,546(79)$ & $0(0)$ \\
$58(16)$ & $50(16)$ & $0(0)$ \\
$18(44)$ & $603(39)$ & $0(0)$ \\
$12(29)$ & $366(24)$ & $1(0)$ \\
$18(27)$ & $7(13)$ & $28(1)$ \\
$3(7)$ & $135(9)$ & $1(0.1)$ \\
$3(7)$ & $33(2)$ & $1(0.1)$ \\
$8(20)$ & $322(21)$ & $187(10)$ \\
$6(39)$ & $552(36)$ & $186(10)$ \\
$10(7)$ & $9(7)$ & $32(2)$ \\
$2(2)$ & $1(2)$ & $232(12)$ \\
& & \\
$2.1(0.6)$ & $3.0(0.9)$ & $0(0)$ \\
$3.4(1.0)$ & $3.7(1.0)$ & $0(0)$ \\
$0.61(0.08)$ & $0.83(0.08)$ & $0(0)$ \\
\hline
\end{tabular}

missing or incomplete spirometry results for some countries (eg, Italy, Supplemental Appendixes 1 and 2), resulting in unreliable prevalence estimates in those countries. We did not record whether missing spirometry data (19\%) arose from uninterpretable results or whether spirometry was not performed in these patients. Moreover, there was no additional standardized reassessment of all spirometry curves in our study, and the individual judgment of quality by the individual research staff members may have led to misclassification.

Participants were assessed using the equipment already available in the participating practices and so were assessed using a range of models and makes of spirometer (list available on request). Spirometry was performed according to a uniform protocol at all study sites, however, and all general practice staff members performing spi- rometry were trained to analyze spirometry curves. A primary care study has shown that spirometry tests in a primary care setting conducted by staff with adequate training are comparable in quality to pulmonary function laboratory measurements. ${ }^{21}$ Finally, participants were included who were using inhaled lung medication, which may have influenced their spirometry results. Even so, it is common for primary care patients to be treated with inhaled medication without first undergoing diagnostic work-up for asthma or COPD.

\section{Comparison With Other Studies}

The prevalence of abnormal spirometry patterns in our study was lower than in other studies. The diagnostic outcomes we used, however, differed from those used in these previous studies. Thiadens and colleagues ${ }^{6}$ found asthma in 39\% and COPD in 7\% of the cases, and Broekhuizen and colleagues ${ }^{7}$ found previously undetected COPD in 30\%. Apart from the older age of participants in Broekhuizen's study, the most likely explanation is that the average duration of cough was shorter in our study (8.7 days, with a self-reported recovery rate of $70 \%$ at 14 days). In an open-population study of the presence of chronic lung diseases in 169 smokers, $18 \%$ had COPD, increasing to $27 \%$ among those with chronic cough. ${ }^{1}$

There was no notable variation in prevalence of airway obstruction among nonsmokers (9\%), past

\section{Table 2. Cough Duration of Adult Patients Consulting for Acute Cough in Primary Care $(\mathrm{N}=1,947)$ by Presence of Bronchodilator Responsiveness and Obstruction}

\begin{tabular}{lccc}
\hline Duration of Cough & $\begin{array}{c}\text { Bronchodilator } \\
\text { Responsiveness } \\
\text { No. (\%) }\end{array}$ & $\begin{array}{c}\text { Obstruction } \\
\text { (GOLD or LLN) } \\
\text { No. (\%) }\end{array}$ & $\begin{array}{c}\text { No Responsiveness } \\
\text { or Obstruction } \\
\text { No. (\%) }\end{array}$ \\
\hline $\begin{array}{l}\text { Total patients } \\
\text { Cough before consultation } \\
<1 \text { week }\end{array}$ & $240(12)$ & $202(10)$ & $1,546(79)$ \\
$1-2$ weeks & $114(12)$ & $94(10)$ & $743(80)$ \\
$2-3$ weeks & $54(11)$ & $53(11)$ & $397(80)$ \\
$>3$ weeks & $47(15)$ & $38(12)$ & $241(77)$ \\
Duration until recovery & $25(12)$ & $17(8)$ & $165(81)$ \\
$<1$ week & $25(11)$ & $21(9)$ & $180(80)$ \\
$1-2$ weeks & $137(13)$ & $114(11)$ & $854(79)$ \\
$2-3$ weeks & $57(12)$ & $48(11)$ & $361(79)$ \\
$>3$ weeks & $21(11)$ & $19(10)$ & $151(80)$ \\
Total cough duration & & & $17(85)$ \\
$<1$ week & $2(10)$ & $1(5)$ & $346(81)$ \\
$1-2$ weeks & $46(11)$ & $41(10)$ & $510(79)$ \\
$2-3$ weeks & $88(14)$ & $71(11)$ & $673(79)$ \\
$>3$ weeks & $104(12)$ & $89(11)$ & \\
\hline GOLD $=$ Global Initiative for Chronic Obstructive Lung Disease; LLN $=$ lower limit of normal. & \\
a Including participants with both bronchodilator responsiveness and obstruction (n= 41). & \\
\hline
\end{tabular}


Figure 2. Prevalence of airway obstruction and bronchodilator responsiveness in patients consulting for acute cough, by diagnostic definition and age-group.

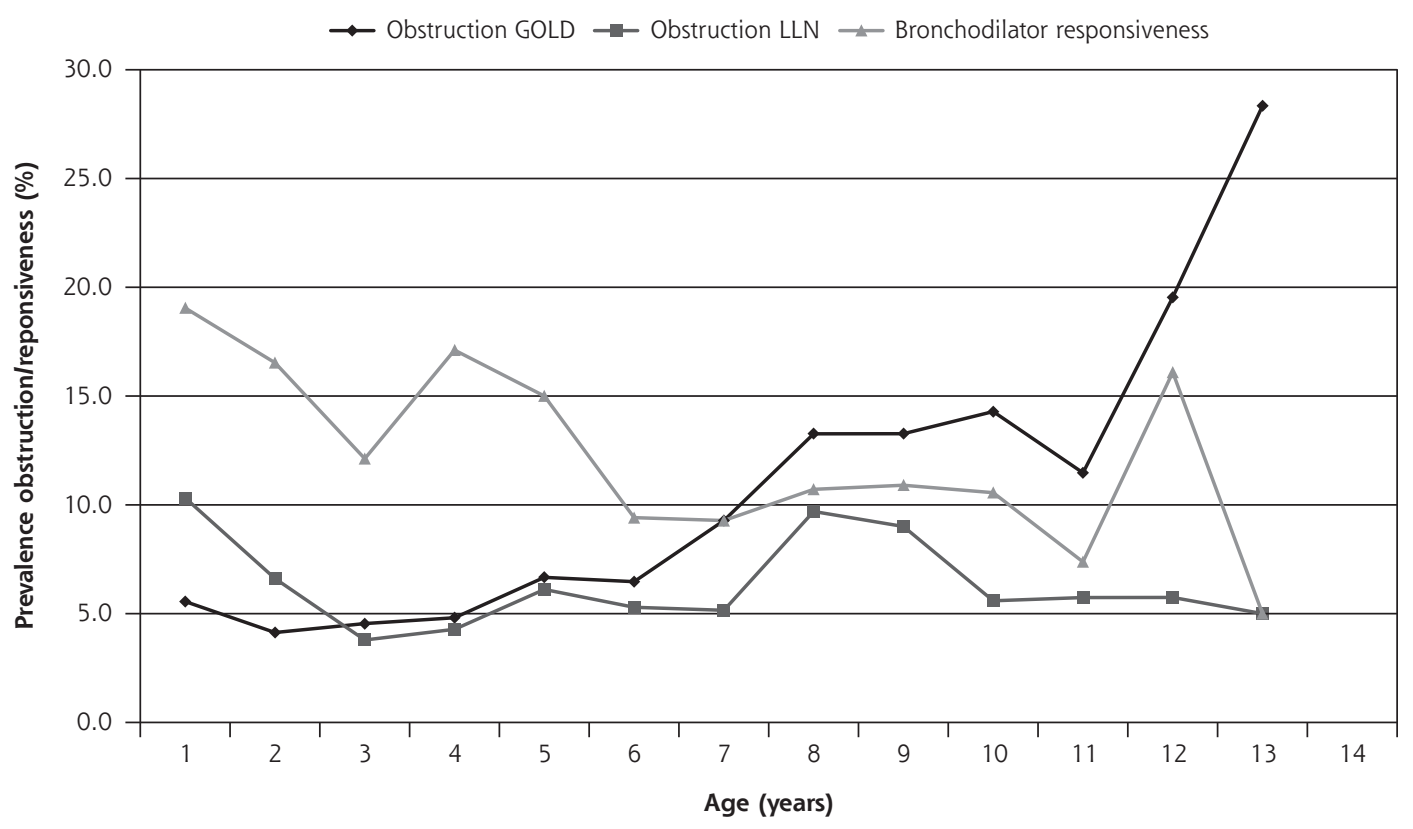

ERS = European Respiratory Society; FEV $1=$ forced expiratory volume in 1 second; FVC = forced vital capacity; GOLD = Global Initiative for Chronic Obstructive Lung Disease; $L L N=$ lower limit of normal.

Note: obstruction GOLD = according to the GOLD definition: FEV 1 :FVC less than 0.70 . Obstruction LLN = according to ERS: LLN of FEV 1 :FVC ratio for male patients: $-0.18 \times$ age $+87.21-(1.64 \times 7.17)$; for female patients: $-0.19 \times$ age $+89.10-(1.64 \times 6.51)$.

smokers $(10 \%)$, and current smokers $(13 \%)$ in our study, which is possibly related to the large number of missing results on smoking status. Alternatively, smokers may have been more likely to have had COPD previously diagnosed.

Studies in the general population found prevalence of obstructive lung disease that varied from $23 \%$ to $29 \%$, depending on diagnostic criteria. ${ }^{17-19}$ Likewise, findings from our study show that differences in age, sex, smoking status, and geographical population, as well as the definition that is used, can result in systematic differences in international prevalence rates. The increasing airway obstruction GOLD prevalence with older age, ie, when using the fixed ratio, is in line with recent warnings for overdiagnosis of airway obstruction in older adults. Also, the higher prevalence according to the LLN definition in younger participants is consistent with previous studies. ${ }^{13}$

\section{Clinical Implications and Conclusions}

An important proportion (approximately one-fifth) of adult patients without an established diagnosis of asthma or COPD consulting their family physician with acute cough showed subsequent airway obstruction or bronchodilator responsiveness, which suggests undetected asthma or COPD. Given effective pharma- cological and lifestyle modification interventions, especially interventions to assist in quitting smoking, identifying and providing appropriate treatment and advice to these patients is likely to improve their quality of life and reduce exacerbations. Moreover, an accurate diagnosis could help to motivate smokers to quit. ${ }^{22}$ Finally, detection of asthma and COPD may help to reduce unnecessary use of antibiotics in patients with acute cough, because a noninfectious cause (obstruction) will also be considered.

Different methods to define airway obstruction resulted in twofold differences in the prevalence estimates among participants aged 50 years or more. Our results from symptomatic patients seeking health care uniquely confirm findings from open-population studies that a fixed cutoff value of 0.70 (GOLD) should be used to define obstruction with caution in the extremes of age. ${ }^{12,13}$

To read or post commentaries in response to this article, see it online at http://www.annfammed.org/content/10/6/523.

Key words: acute cough; asthma; chronic obstructive pulmonary disease; primary health care; spirometry

Submitted September 7, 2011; submitted, revised, March 1, 2012; accepted March 15, 2012. 
Author affiliations: University Medical Center Utrecht, Julius Center for Health, Sciences and Primary Care, Utrecht, the Netherlands (van Vugt, Broekhuizen, Zuithoff, Verheij); Cardiff University, Institute of Primary Care and Public Health Medicine, Cardiff, Wales, United Kingdom (Butler, Hood); University of Antwerp, Vaccine $\&$ Infectious Disease Institute (VAXINFECTIO), Antwerp, Belgium (Coenen, Goossens); Primary Care Medical Group, University of Southampton Medical School, Southampton, United Kingdom (Little, Moore); Intensive Care Unit, Hospital de Mataro, Mataro, Spain (Almirall); Respiratory Medicine Section, Dipartimento Toraco-Polmonare e Cardiocircolatorio, University of Milan, IRCCS Fondazione Cà Granda, Milan, Italy (Blasi); Department of Family Medicine and Community Nursing, Medical University of Bialystok, Bialystok, Poland (Chlabicz); Ely Bridge Surgery, Ely Bridge Surgery, Cardiff, United Kingdom (Davies); Department of Family and Community Medicine, Medical University of Lodz, Lodz, Poland (Godycki-Cwirko); Institute of Microbiology, Faculty of Medicine, Comenius University, Bratislava, Slovakia (Hupkova); Zdravstveni dom Jesenice and University of Ljubljana Medical School, Slovenia (Kersnik); Zentrum für Pneumologie, Diakoniekrankenhaus Rotenburg, Rotenburg, Germany (Schaberg); Ghent University, University Hospital, Ghent, Belgium (De Sutter); Servei de Pneumologia, Institut Clinic del Torax, Barcelona, Spain (Torres).

Funding support: The design and conduct of the study, collection, management, analysis, and interpretation of the data and preparation, review, and approval of the study were all funded by 6th Framework Program of the European Commission (Reference: LSHMCT-2005-518226). In Flanders (Belgium) this work was supported by the Research Foundation, Flanders (G.0274.08N).

Disclaimer: The funding sources were not involved in the design, conduct, analysis, and interpretation of the data, or in the writing and decision to submit the manuscript. There was no pharmaceutical company involved. The corresponding author had full access to the data and had final responsibility for the decision to submit for publication.

Previous presentations: This work was presented at the WONCA congress (September 2011, Warsaw, Poland) and the ERS congress (September 2011, Amsterdam, the Netherlands).

Acknowledgments: We would like to thank the entire GRACE team for their diligence, expertise and enthusiasm. Finally, we are indebted to all of the patients who consented to be part of GRACE, without whom this study would not have been possible.

\section{References}

1. Van Schayck CP, Loozen JM, Wagena E, Akkermans RP, Wesseling GJ. Detecting patients at a high risk of developing chronic obstructive pulmonary disease in general practice: cross sectional case finding study. BMJ. 2002;324(7350):1370-1374.

2. Mannino DM, Homa DM, Akinbami LJ, Ford ES, Redd SC. Chronic obstructive pulmonary disease surveillance-United States, 19712000. MMWR Surveill Summ. 2002;51(6):1-16.

3. Schappert SM, Burt CW. Ambulatory care visits to physician offices, hospital outpatient departments, and emergency departments: United States, 2001-02. Vital Health Stat 13. 2006;(159):1-66.

4. Rabe KF, Hurd S, Anzueto A, et al; Global Initiative for Chronic Obstructive Lung Disease. Global strategy for the diagnosis, management, and prevention of chronic obstructive pulmonary disease: GOLD executive summary. Am J Respir Crit Care Med. 2007;176(6): 532-555.

5. From the Global Strategy for Asthma Management and Prevention, Global Initiative for Asthma (GINA). 2012. http://www.ginasthma .org.
6. Thiadens HA, de Bock GH, Dekker FW, et al. Identifying asthma and chronic obstructive pulmonary disease in patients with persistent cough presenting to general practitioners: descriptive study. BMJ. 1998;316(7140):1286-1290.

7. Broekhuizen BD, Sachs AP, Hoes AW, et al. Undetected chronic obstructive pulmonary disease and asthma in people over 50 years with persistent cough. Br J Gen Pract. 2010;60(576):489-494.

8. Broekhuizen BD, Sachs AP, Oostvogels R, Hoes AW, Verheij TJ, Moons KG. The diagnostic value of history and physical examination for COPD in suspected or known cases: a systematic review. Fam Pract. 2009;26(4):260-268.

9. Hopstaken RM, Coenen S, Butler CC, et al. Prognostic factors and clinical outcome in acute lower respiratory tract infections: a prospective study in general practice. Fam Pract. 2006;23(5):512-519.

10. Damon A. Negro-white differences in pulmonary function (vital capacity, timed vital capacity, and expiratory flow rate). Hum Biol. 1966;38(4):381-393.

11. Boldy DA, Skidmore SJ, Ayres JG. Acute bronchitis in the community: clinical features, infective factors, changes in pulmonary function and bronchial reactivity to histamine. Respir Med. 1990;84(5):377-385.

12. Levy ML, Quanjer PH, Booker R, Cooper BG, Holmes S, Small I; General Practice Airways Group. Diagnostic spirometry in primary care: proposed standards for general practice compliant with American Thoracic Society and European Respiratory Society recommendations. Prim Care Respir J. 2009;18(3):130-147.

13. Swanney MP, Ruppel G, Enright PL, et al. Using the lower limit of normal for the FEV1/FVC ratio reduces the misclassification of airway obstruction. Thorax. 2008;63(12):1046-1051.

14. Quanjer PH, Tammeling GJ, Cotes JE, Pedersen OF, Peslin R, Yernault JC; Official Statement of the European Respiratory Society. Lung volumes and forced ventilatory flows. Report Working Party Standardization of Lung Function Tests, European Community for Steel and Coal. Eur Respir J Suppl. 1993;16:5-40.

15. Anker JD. The Spearman rank-order correlation coefficient. In: Siegel S, Castellan NJ, eds. Nonparametric Statistics for the Behavioral Sciences. New York, NY: McGraw-Hill; 1988: 235-244.

16. R Development Core Team. R: A Language and Environment for Statistical Computing. Vienna, Austria: R Foundation for Statistical Computing; 2008

17. Halbert RJ, Isonaka S, George D, Iqbal A. Interpreting COPD prevalence estimates: what is the true burden of disease? Chest. 2003;123(5):1684-1692.

18. Celli BR, Halbert RJ, Isonaka S, Schau B. Population impact of different definitions of airway obstruction. Eur Respir J. 2003;22(2): 268-273.

19. Viegi G, Pedreschi M, Pistelli F, et al. Prevalence of airways obstruction in a general population: European Respiratory Society vs American Thoracic Society definition. Chest. 2000;117(5)(Suppl 2):339S-345S

20. Stang PF, Lydick E, Silberman CF, Kempel AF, Keating ET. The prevalence of COPD: using smoking rates to estimate disease frequency in the general population. Chest. 2000;117(5)(Suppl 2):354S-359S.

21. Schermer TR, Jacobs JE, Chavannes NH, et al. Validity of spirometric testing in a general practice population of patients with chronic obstructive pulmonary disease (COPD). Thorax. 2003;58(10):861-866.

22. Bednarek M, Gorecka D, Wielgomas J, et al. Smokers with airway obstruction are more likely to quit smoking. Thorax. 2006;61(10): 869-873. 